\section{Questión}

Periodismo / Comunicación ISSN 1669-6581
- Av. $44 \mathrm{~N}^{\circ} 676,1^{\circ}$ piso

CP 1900 - La Plata - Argentina

( www.perio.unlp.edu.ar/question

La escuela en tiempos de Pandemia

Ana María García Munitis

DOI: https://doi.org/10.24215/16696581e313

\title{
La escuela en tiempos de Pandemia
}

\section{The school in times of Pandemic}

Ana María García Munitis / direccion@nacio.unlp.edu.ar Directora del Colegio Nacional "Rafael Hernández" de la UNLP

Si algo ha logrado esta Pandemia es poner en primer plano la importancia de la comunicación. De pronto todos nos hemos vuelto expertos, capaces de juzgar si una noticia fue comunicada correctamente por las autoridades, si los números que dan cuenta, día a día, del avance del virus son reales. Aprendimos que no solo lo que se dice expresamente comunica sino que hay que saber leer entrelíneas, interpretar gestos. Nuestro olfato nos habilita a sospechar que se nos está ocultando información o que lo que se dice es exagerado o poco confiable. Cuestionamos si tanta carga informativa es necesaria, si está bien que el COVID 19 se haya convertido en tema excluyente. Incluso, hay avisos publicitarios en horarios centrales de radio y TV, que piden a sus audiencias que solo se nutran de fuentes confiables y que gradúen el acceso a la información (léase, que no estén todo el día pendientes de las noticias referidas a la Pandemia) dado que produce estados de ansiedad que, sumados al aislamiento, pueden ser nocivos para la salud mental. Así de poderosa es la comunicación. $Y$ así de expuesta ha quedado en este particular contexto donde parecería que todo hecho cobra entidad cuando pasa por el tamiz comunicacional.

Y si de comunicación se trata, la clase constituye un hecho comunicacional por excelencia, que posibilita el desarrollo del proceso de transmisión - adquisición de conocimientos. En consecuencia, debería ser sencillo asumir que todos los factores que giran en torno a la escuela se sostienen fundamentalmente en la comunicación. 
Las medidas de aislamiento preventivo dispuestas por el gobierno nacional, coincidieron con el inicio del ciclo lectivo 2020. La imposibilidad de encontrarnos con nuestros estudiantes en el ámbito de las aulas nos enfrentó, en pocas horas, a una realidad que se venía postergando: la incorporación de las nuevas Tecnologías de la Información y la Comunicación (TIC) al proceso de enseñanza - aprendizaje.

Inmediatamente, en el Colegio Nacional "Rafael Hernández", nos pusimos a trabajar para decidir la forma más sencilla y universal -atendiendo a lo heterogéneo de nuestro alumnadode mantener contacto con los estudiantes.

La primera cuestión a considerar fue la poca experiencia en educación a distancia que tenían la mayoría de nuestros docentes y alumnos así como la falta de certeza acerca de la disponibilidad de dispositivos tecnológicos y de la conectividad necesaria para soportar las plataformas educativas disponibles.

La sensación fue, entonces, que habíamos descuidado una faceta de la formación de nuestro alumnado que en este contexto resultaba indispensable: la educación a distancia. La situación sin precedentes que estamos atravesando, puso en tela de juicio nuestros hábitos a la vez que nos obligó a revisar concienzudamente nuestros sistemas de pensamiento y de toma de decisiones.

Sin embargo, una vez superado el cimbronazo inicial, pudimos ver algo con claridad: la educación en casa no es ni puede ser la escuela. Y esta premisa tan evidente sirvió de norte para la tarea que debíamos realizar.

Si solo contábamos con experiencias puntuales en educación a distancia - como la de Aulas de graduación y los casos de los alumnos que por diversas razones se ven impedidos de asistir a clase- es porque la escuela se construye con la presencia. La escuela son las aulas, los profesores, los compañeros, los no docentes, el timbre, los recreos, la biblioteca, el buffet, los patios, los corredores, que se conjugan para dar vida a una de las instituciones primordiales de nuestra sociedad.

Es sabido que la educación a distancia aumenta las desigualdades, ya que depende de las condiciones materiales, sociales y culturales de las familias. $Y$ es, precisamente, la escuela la encargada de acortar esta brecha. Con esto no queremos decir que la escuela, tal cual la vivimos hoy, haya superado esta problemática. Muy por el contrario. Creemos que es una preocupación constante y una deuda por saldar. Pero estamos convencidos de que es el mejor 
lugar para garantizar el acceso igualitario a conocimientos comunes, para hacernos percibirtal como señala Philippe Merieu - que a pesar de nuestras diferencias, todos estamos llamados a participar en la "construcción de lo común".

La escuela no es una yuxtaposición de intervenciones individuales sino una construcción colectiva, en la que la figura del docente se puede asimilar a la de un artesano que no pierde de vista las singularidades, los detalles, en la construcción de la totalidad de su obra. Existe un ida y vuelta entre lo colectivo y lo individual, entre lo que une a los alumnos y los distingue en sus particularidades, que hace a la esencia de la escuela. Es un claro ejemplo de que el todo no puede reducirse a la suma de las partes. Cada una es importante pero el resultado está más allá de las individualidades y de sus intereses porque a lo que se aspira es al bien común, que permite superarse a uno mismo e invita a ser parte de un todo que encarna valores colectivos.

Otro aspecto tranquilizador fue pensar la escuela como institución transmisora una de cultura de la cual nuestros jóvenes forman parte y que es, en definitiva, un patrimonio, una marca de identidad y un derecho. Esto nos permite distanciarnos de una escuela que mediada por la tecnología digital pueda confundirse con un "servicio" destinado a satisfacer demandas individuales en lugar de constituirse como una institución capaz de garantizar el derecho a la educación de todos nuestros ciudadanos. Con esto no queremos decir que rechazamos el uso de las herramientas digitales que, sin duda, favorecen la comunicación y que en este particular contexto se presentan como nuestras únicas e indispensables aliadas. Sino que tenemos que luchar contra la lógica individual y técnica que las rige en su mayoría para ponerlas al servicio de la construcción de lo colectivo.

Pensar la escuela, más allá de la contingencia, nos trajo la claridad necesaria para ponernos en marcha. Era preciso establecer contacto con el mayor número posible de estudiantes y ofrecerles actividades que los estimularan intelectualmente. Quienes alguna vez hemos estado al frente de un curso, sabemos que la motivación es el punto de partida de nuestras clases. Cuando el alumno no está presente y la interacción pedagógica se ve limitada por las posibilidades que ofrecen los distintos soportes tecnológicos, se corre el riesgo de transformar nuestros objetivos en prerrequisitos. Debemos evitar caer en la confusión de pensar que tanto la motivación como el esfuerzo y la autonomía que esperamos de nuestros alumnos en la resolución de las actividades propuestas, son requisitos previos y no los objetivos de estas actividades que no pueden disociarse de la adquisición de conocimientos. Del mismo modo 
que, en un principio, erramos al pensar que la educación a distancia podría utilizarse para "adelantar el programa" de manera tal que, al retomarse las clases presenciales estaríamos en condiciones de continuar, con algunos ajustes, con nuestras clases habituales.

Hoy, a poco más de un mes de gestionar en este contexto de crisis, más cercano a un relato de ciencia ficción que a nuestra realidad habitual, estamos en condiciones de afirmar que si bien la tecnología tiene formas efectivas de comunicarnos, es insuficiente como sustituto de la materialidad. Paradójicamente, su utilización evidencia lo irreemplazable de la presencialidad en el proceso pedagógico.

Si bien el impulso docente inicial de intentar reemplazar la interacción personal por el uso de la tecnología fue bien intencionado, creemos que pecó de ingenuo. Algo falta en el proceso de comunicación. Del mismo modo que la reproducción, por más exacta que sea, no es la obra de arte, el acto pedagógico no es el mismo fuera del contexto del aula.

La problemática de suponer un acceso universal a las nuevas tecnologías

Mucho se habla del rol de la escuela y de los docentes ante el desafío de educar en épocas de aislamiento social obligatorio. La educación a distancia, que desde hace tiempo ocupa al mundo, hoy se ha vuelto indispensable.

Desde nuestro lugar podríamos pensar varias estrategias educativas posibles en respuesta a la Pandemia, pero si al pensarlas no problematizamos el acceso a las nuevas tecnologías, seguro fallaremos en el cumplimiento de nuestro cometido que no es otro que la llegada a la mayor cantidad de estudiantes posible.

Con el objetivo de mejorar la situación de los alumnos en sus hogares, en términos vinculares y de conectividad, el Colegio Nacional "Rafael Hernández", elaboró un Informe de relevamiento, correspondiente al período del 17 al 22 de abril del corriente.

Los resultados arrojados son fundamentales para el ajuste y la elaboración de las tareas de continuidad pedagógica programadas por la institución. La encuesta, que da origen al informe, hace foco en el acceso, la conectividad y la disponibilidad de los jóvenes de un dispositivo tecnológico, ya sea celular, computadora o tablet.

Las problemáticas que se presentan con las actividades de continuidad pedagógica, según señalaron los encuestados son, en primer lugar, el uso compartido del dispositivo electrónico y, en segundo lugar, el contenido de las tareas. También se registran, en menor medida, 
dificultades con los plazos de entrega de las actividades solicitadas por los profesores y con la comunicación con los docentes vía e-mail.

Si bien el $94 \%$ de los encuestados cuenta con acceso Internet, el $46 \%$ tiene una conexión mala o nula. Del total de los encuestados, solo el $50 \%$ tiene buena conectividad.

Respecto a las herramientas utilizadas para realizar las actividades, la mayoría utiliza el celular $(47,5 \%)$ o una computadora de uso compartido (45\%). Esto dificulta la organización familiar y el cumplimiento en tiempo y forma de las mismas.

La problemática de falta de fluidez en la comunicación con los docentes genera que el 40,4\% de los estudiantes no comprenda el contenido de las tareas solicitadas y, por consiguiente, dificulta el cumplimiento de los plazos de entrega.

En esta primera etapa se relevaron 184 familias, cuyo/s hijo/s tienen o solicitaron beca o algún tipo de asistencia a la institución. Esta tarea fue realizada por preceptores mediante llamadas telefónicas.

Más allá del acceso a las nuevas tecnologías o a cuestiones vinculadas con la conectividad, existen factores que necesariamente deben ser tomados en cuenta al momento de diseñar una estrategia pedagógica. Tal es el caso de las familias que, en esta situación de aislamiento, han visto reducidos sus ingresos de manera significativa -el $65 \%$ de la muestra- y no recibe ayuda económica de ningún tipo. Otros grupos familiares han manifestado que su único medio de subsistencia es la asistencia que reciben por parte del Estado (AUH, IFE, Fondo de desempleo, Bolsones de comida).

Por último, en respuesta a estas problemáticas, algunas familias sugieren implementar como metodologías alternativas las clases virtuales y/o videollamadas para explicar contenidos (36.4\%) mientras que, en otros casos, solicitan material impreso o computadoras (20\%).

La escuela después

En mis años al frente del equipo de gestión del Colegio Nacional, he repetido muchas veces que la educación es nuestra apuesta fuerte al futuro. Hoy, no puedo evitar cuestionarme acerca de ese futuro. No puedo dejar de pensar en los posibles escenarios para los que debemos preparar a nuestros estudiantes. Cómo será el mundo que sobrevendrá a la crisis, cómo será ese "futuro" del que tantas veces hablé. 
Creo que nadie duda que habrá un antes y un después de esta Pandemia. Un cambio de paradigma. Sin embargo son pocos los que se atreven a aventurar en qué consistirá ese "después".

Frente a los pronósticos pesimistas no puedo más que pararme en la vereda opuesta. Es imposible estar al frente de una institución a la que concurren diariamente mil ochocientos jóvenes, de entre doce y dieciocho años, si no se tiene una mirada esperanzadora sobre el futuro. Vamos a volver a las aulas transidos por una experiencia de la que forzosamente, quienes somos responsables de la educación de nuestros jóvenes, tenemos que sacar una enseñanza positiva.

¿Cómo será el nuevo orden? ¿Qué le aguarda a la escuela?

Son muchos los pedagogos que advierten que bajo las nuevas tecnologías digitales que se aplican a la educación se reproduce, sin embargo, el viejo modelo conductista de la enseñanza. Para otros, las aulas web son una especie de "Gran Hermano", un ojo panóptico reñido con la privacidad al revelar a quienes las administran los hábitos de sus estudiantes.

Sin duda, los tecnócratas tomarán esta experiencia como una prueba cabal de la prescindibilidad de la escuela tradicional, con sus profesores y sus rituales de horarios que cumplir, asistencia a clase, evaluaciones. Muchos verán en la gestión tecnocrática y en la educación a distancia el derrotero inevitable del futuro de la institución escolar.

Sin embargo, si algo está quedando en evidencia es que los entornos virtuales, aún mediados por docentes, requieren de formas estandarizadas, de ejercicios programados, de protocolos que distan mucho de las realidades de nuestras aulas.

Por eso espero que la escuela del después pueda despertar del encanto de las herramientas tecnológicas para ser capaz de cuestionar su aplicación y decidir su incidencia en el futuro.

Al mismo tiempo, resulta evidente que la escuela tendrá un alto grado de participación en la construcción de ese futuro.

La Pandemia ha dejado al descubierto muchas miserias humanas pero también ha servido para derribar fronteras y acrecentar la solidaridad entres los pueblos. Ha enseñado de manera brutal el verdadero significado de vivir en un mundo globalizado.

Me gustaría poder cerrar con la certeza de que la humanidad está avanzando hacia una mayor conciencia de los problemas que la aquejan, hacia una mayor justicia social, sin importar ya las 
diferencias entre primer mundo y países emergentes, entre las grandes potencias y el resto de las naciones.

Si una enseñanza nos está dejando esta penosa situación es que todos necesitamos del otro, que la solidaridad es la respuesta.

Imagino un regreso a las aulas con una nueva escala de valores, en la que las experiencias personales puedan ser compartidas y la comunicación sea la instancia superadora del trauma. Aulas con estudiantes que prioricen su curiosidad, su espíritu crítico por sobre el consumismo que impone la sociedad de mercado. Aulas con estudiantes que cuestionen, que se resistan a aceptar verdades reveladas porque vienen de una experiencia para la que no había respuestas. Aulas con estudiantes que se sientan verdaderamente ciudadanos del mundo porque esta Pandemia les ha demostrado la inutilidad de las fronteras. Aulas con alumnos solidarios que encuentren que la verdadera felicidad está en compartir, en comunicar conocimientos, aprendizajes, experiencias, cultura, arte, recursos inagotables que esperamos se transformen en las nuevas riquezas del nuevo orden.

Para cerrar, comparto una frase de La peste de Albert Camus: "algo que se aprende en medio de las plagas: que hay en los hombres más cosas dignas de admiración que de desprecio". 